\title{
Effects of Plant Density on Boll Retention and Yield of Cotton in the Mid-South
}

\author{
Jack C. McCarty, Johnie N. Jenkins, Russell W. Hayes, Martin J. Wubben \\ Genetics and Sustainable Agriculture Research Unit, Crop Science Research Laboratory, USDA-ARS, Starkville, MS, USA \\ Email: jack.mccarty@ars.usda.gov
}

How to cite this paper: McCarty, J.C., Jenkins, J.N., Hayes, R.W. and Wubben, M.J. (2017) Effects of Plant Density on Boll Retention and Yield of Cotton in the MidSouth. American Journal of Plant Sciences, 8, 891-906.

https://doi.org/10.4236/ajps.2017.84060

Received: February 15, 2017

Accepted: March 28, 2017

Published: March 31, 2017

Copyright $\odot 2017$ by authors and Scientific Research Publishing Inc. This work is licensed under the Creative Commons Attribution International License (CC BY 4.0).

http://creativecommons.org/licenses/by/4.0/ c) (i) Open Access

\begin{abstract}
The number of cotton (Gossypium hirsutum L.) plants being grown per unit of land area has gained attention due to the technology fees associated with seed containing value added traits. We investigated boll retention, yield, and yield components of cotton grown with reduced stands of $20 \%$ to $40 \%$ from the uniform planting pattern of four seeds per $30.5 \mathrm{~cm}$ of row. Five field experiments were conducted from 2012-2014 using eight treatments arranged in a randomized complete design with six replications. Yield and yield component data were collected. The plant one-row skip one-row treatment resulted in significant yield losses across all five experiments compared to the uniform planting pattern. Treatments with $20 \%$ stand reductions did not result in lower total yields; however, each plant in these treatments had to produce two additional bolls to maintain yield. Treatments which had at least $61 \mathrm{~cm}$ skips, $40 \%$ stand reduction, resulted in lower yields. Treatments had minor affects on boll weight, and lint percentage. The uniform planting pattern produced $67 \%$ of its yield from position one bolls compared to about $50 \%$ for treatments with reduced stands. Reduced stand treatments produced about $20 \%$ of their yield on monopodial branches compared to $10 \%$ for the uniform treatment. With modern precision planting equipments, opportunities exist to reduce seed rate and maintain yield; however, many production risk factors must also be considered before a reduced seeding rate is adopted.
\end{abstract}

\section{Keywords}

Cotton, Plant Population, Fruit Retention, Plant Skips

\section{Introduction}

Even though Upland cotton, Gossypium hirsutum L., is widely grown and provides a source of natural fibers for the textile industry, production challenges remain. The current economic climate continues to impact profit margins. With 
production cost on the rise due in part to increased seed cost associated with transgenic technologies, producers are searching for ways to increase efficiency. This has led to changes in seeding rates, row spacing and row-configurations such as solid planted, twin-rows, and skip-row patterns. With the advent of precision seed drop planters and GPS control systems, producers can manipulate plant populations to optimize yield.

Several studies conducted in the late 1800's and early to mid 1900's suggested that a wide range in plant stand resulted in yields being similar. Plant stands in those studies were sparse compared to today. For example Mayton et al. [1] reported on experiments conducted in Alabama from 1924 to 1935. In the first set of experiments conducted during 1924-1929, cotton plants were spaced 6, 12, 18, 30 , and 36 inches apart in 3.5 foot rows with one, two, three, and four plants per hill. Based on results obtained, a second set of experiments were conducted from 1930-1934 at five branch stations each year with spacing of 9, 18, and 27 inches with one, three, and six plants per hill at each drill distance. Based on the ten years study, they recommended that cotton be spaced 18 inches apart in the drill with one to three plants per hill.

With the introduction of mechanical harvesters, there was renewed interest in plant stand and population density. Wilkes and Corley [2] reviewed the results of numerous studies and concluded that plant spacing could vary considerably and produce similar yields as long as plants were uniformly distributed. They further reported that 40,000 to 50,000 plants per acre were needed for efficient mechanical harvesting.

Studies have continued to be conducted since the 1970's in cotton using different plant densities and measuring their effects on total yield [3] [4] [5] [6] [7] [8] [9]. A wide range of plant densities (35,000 to 175,000 plants ha $^{-1}$ ) resulted in optimum total yields in these studies. O'Berry et al. [10] reported that cotton yields were highest with plant populations of 8.9 and $12.8 \mathrm{~m}^{-2}$ compared to 5.3 $\mathrm{m}^{-2}$ in studies conducted in Virginia and North Carolina, while in Louisiana the highest yields were from 5.8 and 9.5 plants $\mathrm{m}^{-2}$ compared to 17.1 plants $\mathrm{m}^{-2}$. McCarty et al. [11] reported that plant spacing of $8,15,23$, and $30 \mathrm{~cm}$ resulted in similar yields in 2003, but yields were significantly affected by plant spacing in 2004. Pettigrew et al. [12] in a study with obsolete and modern cotton genotypes grown at densities of five plants $\mathrm{m}^{-2}$ and 10 plants $\mathrm{m}^{-2}$ reported there was no difference in yield between the two densities. Producers today, in the Mid-South, generally use about a 96.5 to $101.5 \mathrm{~cm}$ row and plant 3 to 4 seeds $30 \mathrm{~cm}^{-1}$ of row, with a final plant population of between 100,000 to 120,000 plants $^{-1} \mathrm{a}^{-1}$.

Cotton yield is directly related to the number of bolls retained to harvest and their weight. Boll retention is complex and can be affected by many interacting factors such as genetics, physiology, nutrition, water stress, temperature, competition for photosynthates, insects or a combination of any of these [3] [13] [14] [15] [16]. These same factors can also affect boll weight. The ability to compensate for reduced plant densities by producing more fruit on longer sympodial branches and producing more main stem nodes or the compensation for loss of 
shed fruit can affect boll retention and weight [3] [17] [18].

Boll retention from Mid-South cotton studies with four seed per $30.5 \mathrm{~cm}(1 \mathrm{ft})$ spaced $7.6 \mathrm{~cm}$ ( $3 \mathrm{in})$ apart show that fruiting sites 1 and 2 on sympodial branches typically produce $50 \%-75 \%$ and $15 \%-20 \%$ of total yield, with the remaining $5 \%-15 \%$ occurring at more distal sites and on monopodial branches [13] [19] [20] [21] [22]. Jenkins et al. [21] reported that bolls at fruiting site 1 were $14 \%$ heavier than bolls at fruiting site 2 and $21 \%$ heavier than those at fruiting site 3 at every node.

The overall goal of this study was to determine the impact of skip size (length) on yield, within canopy yield distribution, and boll size. The objectives of this research were to investigate the effects on boll retention, yield, and yield components of cotton plants grown at different spacing and planting patterns. Treatments were designed to reduced stands approximately 25 and 50\% from standard or uniform planting practices.

\section{Materials and Methods}

\subsection{Experimental Site, Design, and Establishment}

Experiments were conducted at two locations at the Plant Science Research Center, Mississippi State, MS in 2012-2013 and one location in 2014. The soil type at location one was a Marietta sandy clay loam (fine-loamy, siliceous, active, thermic Fluvaquentic Eutrudepts) and at location two a Marietta loam (fineloamy, siliceous, active, thermic Fluvaquentic Eutrudepts). Based on soil analyses $67 \mathrm{kgha}^{-1}$ of $\mathrm{K}_{2} \mathrm{O}$ and $58 \mathrm{kgha}^{-1}$ of $\mathrm{N}$ were applied pre-plant to all plots. At pin head square all plots were side dressed with $78 \mathrm{kgha}^{-1}$ of $\mathrm{N}$. Plots were kept weed free by spot spraying with roundup as needed. Insecticides were applied based on scouting and thresholds. Plants were grown under rain fed conditions without supplemental irrigation. Plant growth regulators were not applied to this study. The cotton cultivar PhytoGen ${ }^{\otimes}$ PHY 375 WRF was used in this study as it was the most popular cotton cultivar planted in the U.S. in 2011 occupying $11 \%$ of all Upland acres; whereas, in the South Central and Southeast states it was planted on 21 and $22 \%$, respectively [23].

Plots were planted on 21 and 22 May 2012, 15 and 16 May 2013, and 21 May 2014 (Table 1). Plots were planted with a six row Monosem ${ }^{\circ}$ precision vacuum planter (Edwardsville, KS) modified by Seed Research Equipment Solutions (SRES), South Hutchinson, KS for planting research plots. The seeding rate was 13 seed per $\mathrm{m}$ spaced $7.6 \mathrm{~cm}$ apart. Each plot was six rows wide on $0.97 \mathrm{~m}$ centers, with a length of $12 \mathrm{~m}$. Approximately three weeks after emergence each year plots were hand thinned to the desired spacing. The experiment contained eight treatments each replicated six times arranged as a randomized complete block. Table 2 provides an illustration of how the treatments were laid out in the field. Treatments were 1) Skips $30.5 \mathrm{~cm}$; rows 1, 3, and 5 were not thinned; in rows 2,4 , and 6 the rows were sub-divided into $30.5 \mathrm{~cm}$ blocks and in every other block going down the row plants were removed; 2) Skips $61 \mathrm{~cm}$; rows 1, 3, and 5 were not thinned; rows 2, 4, and 6 were sub-divided into $61 \mathrm{~cm}$ blocks and 
Table 1. Treatments, experiment number, planting and harvest dates for 5 experiments in 2012-2014 at the Plant Science Research Center Farm, Mississippi State, MS.

\section{Treatment ${ }^{\dagger}$}

1. Skip $30.5 \mathrm{~cm}=$ row 1,3 , and 5 not thinned; row 2,4 , and 6 with $30.5 \mathrm{~cm}$ skips

2. Skip $61.0 \mathrm{~cm}=$ row 1,3 , and 5 not thinned; row 2,4 , and 6 with $61.0 \mathrm{~cm}$ skips

3. Skip $91.5 \mathrm{~cm}=$ row 1,3 , and 5 not thinned; row 2,4 and 6 with $91.5 \mathrm{~cm}$ skips

4. Staggered skip $30.5 \mathrm{~cm}=$ row 1,3 , and 5 with $30.5 \mathrm{~cm}$ skips; row 2, 4, and 6 with $30.5 \mathrm{~cm}$ skips staggered.

5. Staggered skip $61.0 \mathrm{~cm}=$ row 1,3 , and 5 with $61.0 \mathrm{~cm}$ skips; row 2,4 , and 6 with $61.0 \mathrm{~cm}$ skips staggered.

6. Staggered skip $91.5 \mathrm{~cm}=$ row 1,3 , and 5 with $91.5 \mathrm{~cm}$ skips; row 2, 4, and 6 with $91.5 \mathrm{~cm}$ skips staggered.

7. uniform planting pattern $=$ plant 13 seed per $\mathrm{m}$, spaced $7.62 \mathrm{~cm}$ apart

8. skip-row $=$ plant 1 row, skip 1 row

Location and experiment $\begin{gathered}\text { Planting } \\ \text { date }\end{gathered}$ Box map date Machine harvest

\begin{tabular}{|c|c|c|c|}
\hline Loc 1, Exp. 1 & 22 May 2012 & Not mapped & 27 Oct 2012 \\
\hline Loc 2, Exp. 2 & 21 May 2012 & $29-30$ Oct 2012 & 31 Oct 2012 \\
\hline Loc 1, Exp. 3 & 16 May 2013 & Not mapped & 15 Oct 2013 \\
\hline Loc 2, Exp. 4 & 15 May 2013 & 23-24 Oct 2013 & 25 Oct 2013 \\
\hline Loc 1, Exp. 5 & 21 May 2013 & $23-24$ Oct 2014 & 24 Oct 2014 \\
\hline
\end{tabular}

${ }^{\dagger}$ All plots were planted at a seeding rate of 13 seeds equally spaced per $\mathrm{m}$ of row. In treatments $1-3$ we created skips of $30.5,61$, and $91.5 \mathrm{~cm}$ in every other row in the plot. In treatments $4-6$ we created skips of $30.5,61$, and $91.5 \mathrm{~cm}$ in every row but skips were arranged in a staggered fashion in the plot. Treatment 7 was a uniform planting pattern and 8 was a plant one row, skip one row pattern.

Table 2. Illustrations for the first $3.66 \mathrm{~m}$ of row for eight different plant spacing treatments ${ }^{\dagger}$. Each " $x$ " represents $30.5 \mathrm{~cm}$ of row with plants present and the shaded blocks are skips where plants were removed.






\section{Continued}

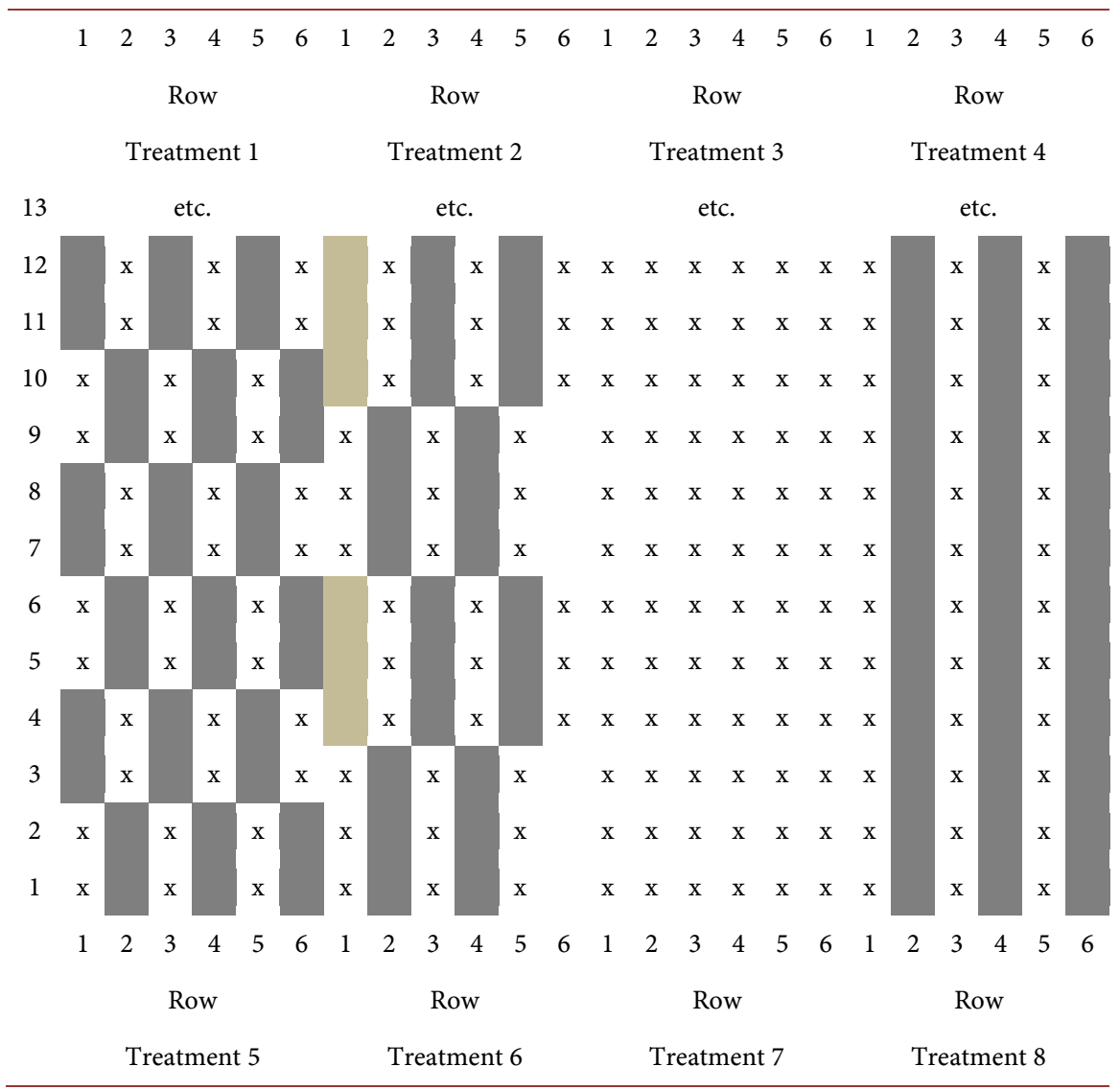

${ }^{\dagger}$ Each treatment was 6 rows wide and $12 \mathrm{~m}$ long. Treatments were arranged in a RCB design with six replications.

plants were removed in every other block going down the row; 3) Skips $91.5 \mathrm{~cm}$; rows 1,3 , and 5 were not thinned; rows 2 , 4 , and 6 were sub-divided into 91.5 $\mathrm{cm}$ blocks and plants were removed in every other block going down the row; 4) Staggered skips $30.5 \mathrm{~cm}$; all six rows were divided in $30.5 \mathrm{~cm}$ blocks and in rows 1,3 , and 5 , plants were removed in blocks $2,4,6$, etc. and for rows 2,4 , and 6 plants were removed in blocks 1, 3, 5 and etc.; 5) Staggered skips $61 \mathrm{~cm}$; the six rows were divided into $61 \mathrm{~cm}$ blocks and in rows 1,3 , and 5 plants were removed in blocks $2,4,6$, etc. and for rows 2,4 , and 6 plants were removed in blocks 1, 3, 5 and etc.; 6) Staggered skips $91.5 \mathrm{~cm}$; the six rows were divided into $91.5 \mathrm{~cm}$ blocks and in rows 1,3 , and 5 plants were removed in blocks $2,4,6$, etc. and for rows 2, 4, and 6 plants were removed in blocks 1, 3, 5 and etc.; 7) Uniform planting pattern; the six row plot was not thinned and; 8) Skip-row; row 1, 3 , and 5 were not thinned and all plants were removed from rows 2,4 , and 6 . In treatments 1 - 3 we created skips of 30.5,61, and $91.5 \mathrm{~cm}$ in every other row in the plot to reduce stand approximately $25 \%$. In treatments $4-6$ we created skips of $30.5,61$, and $91.5 \mathrm{~cm}$ in every row but skips were arranged in a staggered fashion in the plot to reduce stand approximately $50 \%$. Treatment 7 was a uniform planting pattern and 8 was a plant one row, skip one row pattern which reduced stand $50 \%$. Data were collected from the 4 center rows in each treatment. 


\subsection{End-of-Season Plant Mapping}

After defoliation when mature bolls were open, all plants within a continuous 3 $\mathrm{m}$ section of row, selected at random in each plot in locations 2,4 , and 5 were mapped following a described procedure [20] [21] which is commonly referred to as box mapping. For treatments $1-7$, the $3 \mathrm{~m}$ sample came from row 2 in each plot and for treatment 8 the sample came from row 3. Briefly, the mapping procedure involves cutting the plants below the cotyledon node, removing monopodial branches and then moving the plants to the mapping area at the edge of the field. The number of plants was recorded for each sample. Bolls from each plant were hand harvested by fruiting site using a harvest box constructed with labeled (node and position) compartments, hence the term box mapping. The number of bolls harvested by fruiting site was recorded and the seed cotton was placed in labeled bags for weighing. Since a limited number of bolls were harvested on fruiting sites beyond position 3 they were combined with position 3 ( $\geq 3$ ) for data analyses. The bolls from monopodial branches were counted, harvested by bulk and placed in labeled bags. If there was an aborted terminal plant in a sample that could not be mapped, bolls were counted, harvested and placed in a labeled bag. This allowed us to account for total yield in the $3 \mathrm{~m}$ sample. All harvested samples were transported to the laboratory and weighed. From this data we calculated the number of bolls, the weight of seed cotton, and the weight per boll for seed cotton produced at each fruiting site on sympodial branches, and also boll weight and amount of seed cotton produced on monopodial branches. The weight of seed cotton and number of bolls were then converted to percentages for each sympodial fruiting site and the monopodial branch in each sample. The machine harvested seed cotton yield for each treatment was converted to lint yield and this was distributed across fruiting sites according to the percentage distribution from the mapped plants for the three $\mathrm{m}$ sample for each plot. Thus, the yields reported are machine-harvest yields from the mean of the four center rows of each plot. In this manuscript mapping data is presented for position 1, position 2, and position $\geq 3$ fruiting sites from sympodial branches and for monopodial branches for the eight treatments. Analyses of variances (ANOVA) were conducted using SAS version 9.4 (SAS Institute, Cary, NC) and means were separated using Fisher's protected least significant difference (LSD) at the 0.05 level.

\subsection{Yield Data}

A 25-boll sample was hand-picked from row 2 and 3 in each plot prior to machine harvest from near the middle nodes of the plants. Samples were ginned on a 10 saw laboratory gin and used to estimate lint percent and boll weight. The average lint percent across reps was used to convert seed cotton yield to lint yield. A commercial cotton picker modified for plot harvesting and weighing was used to determine yield. Plots were machine harvested on 27 and 31 Oct. 2012, 15 and 25 Oct. 2013 for experiments 1, 2, 3 and 4, respectively and 24 Oct. 2014 for experiment 5. Yield data were subjected to ANOVA using SAS version 
9.4 (SAS Institute, Cary, NC). Means were separated using Fisher's protected least significant difference (LSD) at the 0.05 level. All F-tests were performed as described by McIntosh [24].

\section{Results and Discussion}

\subsection{Plant Population}

All plots were seeded at a rate of 4 seed per $30.5 \mathrm{~cm}$ or 135,967 seed per ha. We expected 3 of the 4 seed to germinate and establish which should have resulted in 101,975 plant per ha in treatment 7 (uniform planting pattern). Based on number of plants mapped at the end of the season the number of plants per ha per treatment were as follows: 1). 70,453; 2). 74,750; 3). 73,523; 4). 54,364; 5). 56,629; 6). 52,854; 7). 89,285; and 8). 47,096. Skip treatments 1 - 3, and staggered skip treatments 4 - 6 should have resulted in a $25 \%$ and $50 \%$ reduction in plant population, which would have been 76,481 and 50,987 plant per ha, respectively. Our uniform planting pattern had about 12,000 fewer plants per ha than expected. Relative to the uniform planting pattern, plant population reductions ranged from $17 \%-22 \%$ for skip treatments $1-3$ and $36 \%-40 \%$ for staggered skip treatments $4-6$. Treatment 8 (skip-row) was reduced $47 \%$. The reductions in population were less than our goal but they did approximate those we wanted to achieve.

\subsection{Yield and Yield Components}

\subsubsection{Boll Weight}

When averaged across all experiments, treatments did not affect boll weight; however, in experiment one in 2012 and experiment three in 2013 some small significant differences were noted (Table 3 ). In a study where plants were spaced from 8 to $30 \mathrm{~cm}$ apart, boll weight increased as spacing increased [11]. Bridge et al. [5] reported that in a study where plant population ranged from 24,700 to 222,300 plants per ha there was a general decrease in boll weight as plant population increased. Our study involved wider skips, not wider spacing between plants; therefore, we did not expect to see major differences in boll weight.

\subsubsection{Lint Percent}

Staggered skips of 30.5 and $61 \mathrm{~cm}$, and skip-row produced higher lint percentages than the uniform planting pattern, when averaged across all experiments (Table 3 ) indicating that reducing plant stand by approximately $50 \%$ increased lint percent. In four of the five experiments we did not detect a significant difference in mean lint percentage across all treatments. As with boll weight we did not expect to see large differences in lint percentage.

\subsubsection{Lint Yield}

Treatments significantly affected lint yield (Table 3). We expected skip-row (treatment 8) to produce lower yields since yield was calculated on a unit of land area for all treatments. Yield for skip-row was significantly lower than all staggered treatments even though plant populations were similar indicating that 
Table 3. Mean boll weight, lint percentage, and lint yield for cotton cultivar PHY 375 WRF grown in different plant spacing treatments in 5 experiments in 2012-2014 at the Plant Science Research Center Farm, Mississippi State, MS.

\begin{tabular}{|c|c|c|c|c|c|c|}
\hline & Exp. 1 & Exp. 2 & Exp. 3 & Exp 4 & Exp. 5 & Mean \\
\hline \multirow{2}{*}{ Treatment $^{\dagger}$} & \multicolumn{6}{|c|}{ Boll weight } \\
\hline & g & g & g & g & g & g \\
\hline 1. Skip 30.5 & 5.42 & 5.25 & 5.31 & 5.55 & 5.46 & 5.40 \\
\hline 2. Skip 61.0 & 5.34 & 5.17 & 5.36 & 5.28 & 5.35 & 5.30 \\
\hline 3. Skip 91.5 & 5.70 & 5.14 & 5.11 & 5.40 & 5.34 & 5.34 \\
\hline 4. Staggered 30.5 & 5.72 & 5.24 & 5.22 & 5.42 & 5.28 & 5.38 \\
\hline 5. Staggered 61.0 & 5.43 & 5.30 & 5.20 & 5.48 & 5.48 & 5.38 \\
\hline 6. Staggered 91.5 & 5.42 & 5.17 & 5.34 & 5.39 & 5.35 & 5.34 \\
\hline 7. uniform & 5.50 & 5.22 & 5.23 & 5.37 & 5.23 & 5.31 \\
\hline 8. skip-row & 5.43 & 5.46 & 5.56 & 5.29 & 5.38 & 5.42 \\
\hline Trt F & * & ns & * & ns & ns & ns \\
\hline Trt by Exp F & & & & & & * \\
\hline \multirow[t]{3}{*}{ Trt LSD (0.05) } & 0.25 & & 0.24 & & & 0.11 \\
\hline & \multicolumn{6}{|c|}{ Lint percentage } \\
\hline & $\%$ & $\%$ & $\%$ & $\%$ & $\%$ & $\%$ \\
\hline 1. Skip 30.5 & 42.06 & 42.05 & 43.97 & 45.17 & 46.36 & 43.92 \\
\hline 2. Skip 61.0 & 43.08 & 42.04 & 43.78 & 45.04 & 46.61 & 44.11 \\
\hline 3. Skip 91.5 & 42.97 & 41.73 & 44.07 & 44.83 & 46.41 & 44.00 \\
\hline 4. Staggered 30.5 & 43.17 & 42.28 & 44.54 & 44.86 & 46.62 & 44.29 \\
\hline 5. Staggered 61.0 & 42.88 & 42.72 & 43.72 & 45.43 & 46.77 & 44.31 \\
\hline 6. Staggered 91.5 & 42.80 & 42.02 & 43.70 & 45.39 & 46.13 & 44.01 \\
\hline 7. uniform & 42.64 & 41.63 & 43.58 & 44.82 & 46.44 & 43.82 \\
\hline 8. skip-row & 43.03 & 42.59 & 44.19 & 45.12 & 46.64 & 44.31 \\
\hline Trt F & $\mathrm{ns}$ & ns & * & ns & ns & $* *$ \\
\hline Trt by Exp F & & & & & & ns \\
\hline \multirow[t]{3}{*}{ Trt LSD (0.05) } & & & 0.58 & & & 0.32 \\
\hline & \multicolumn{6}{|c|}{ Lint yield } \\
\hline & $\mathrm{kg} \cdot \mathrm{ha}^{-1}$ & $\mathrm{~kg} \cdot \mathrm{ha}^{-1}$ & $\mathrm{k} \cdot \mathrm{ha} \mathrm{a}^{-1}$ & $\mathrm{~kg} \cdot \mathrm{ha}^{-1}$ & $\mathrm{~kg} \cdot \mathrm{ha}^{-1}$ & $\mathrm{~kg} \cdot \mathrm{ha}^{-1}$ \\
\hline 1. Skip 30.5 & 1591 & 1473 & 1268 & 1525 & 1648 & 1501 \\
\hline 2. Skip 61.0 & 1691 & 1418 & 1405 & 1536 & 1685 & 1547 \\
\hline 3. Skip 91.5 & 1681 & 1347 & 1360 & 1550 & 1679 & 1524 \\
\hline 4. Staggered 30.5 & 1708 & 1431 & 1288 & 1296 & 1654 & 1476 \\
\hline 5. Staggered 61.0 & 1616 & 1325 & 1182 & 1511 & 1684 & 1463 \\
\hline 6. Staggered 91.5 & 1517 & 1263 & 1099 & 1374 & 1636 & 1378 \\
\hline 7. uniform & 1660 & 1302 & 1440 & 1515 & 1775 & 1538 \\
\hline 8. skip-row & 1242 & 1026 & 903 & 1072 & 1194 & 1087 \\
\hline Trt F & $* *$ & $* *$ & $* *$ & $* *$ & $* *$ & $* *$ \\
\hline Trt by Exp F & & & & & & * \\
\hline Trt LSD (0.05) & 121 & 102 & 151 & 245 & 122 & 68 \\
\hline
\end{tabular}

*, ${ }^{* *}$ significant at the 0.05 and 0.01 levels of probability, respectively; ${ }^{\dagger}$ See table 1 and 2 for treatment description; ${ }^{\ddagger} \mathrm{ns}$, nonsignificant at the 0.05 probability level. 
planting pattern was important in determining total yield. The uniform planting pattern was not significantly different from all skip treatments and staggered skips of $30.5 \mathrm{~cm}$ when averaged across all experiments. Previous studies have shown a wide range in plant populations can result in similar yields; however, most of these studies were conducted with uniform stands. In the current study we reduced plant population by creating different length skips going down the row in the plot. Staggered skips of $61 \mathrm{~cm}$ reduced stand about $36 \%$ and yield was only decreased in one of five experiments compared to the uniform planting pattern. Averaged over the five experiments, only staggered skips of $91.5 \mathrm{~cm}$ and skip-row resulted in significant lower yields compared to the uniform planting pattern. There was a small treatment by experiment interaction. The skip-row pattern resulted in significantly lower yield compared to the uniform planting pattern in all experiments; whereas, in experiments 1 and 5 only staggered skips of $91.5 \mathrm{~cm}$ was lower than the uniform planting pattern. Heilman et al. [25] found that in single drill cotton rows in the Rio Grande Valley of Texas, stand losses of 25 and $40 \%$ resulted in 16.8 and $23.2 \%$ reduction in yield. In a four year test on the High Plains of Texas, a $25 \%$ plant loss resulted in significant yield losses 3 out of 4 years [26].

\subsubsection{End-of-Season Plant Mapping}

The data for mapping are averaged across the three experiments that were mapped (one experiment each year). Lint yields produced on position 1, 2, and $\geq$ 3 fruiting sites on sympodial branches were significantly affected by treatments (Table 4). Uniform planting pattern produced significantly more yield and skip-row produced significantly less yield on position 1 sites than other treatments. Cumulative yield for first position fruiting sites was higher at each main stem node above 8 for the uniform planting pattern compared to the other treatments (data not shown). More lint was produced on position 2 sites for all skip treatments and staggered skips of $30.5 \mathrm{~cm}$ compared to the uniform treatment. All treatments produced greater yields than the uniform planting pattern on position $\geq 3$ sites, except the skip-row. Also, all treatments produced greater yields from monopodial branches compared to the uniform treatment. When we examined cumulative yields across position 1,2, $\geq 3$ and monopodial branches, the only treatments that were different from the uniform planting pattern were staggered skips of $91.5 \mathrm{~cm}$ and skip-row (Table 4); however, the uniform planting pattern accumulated higher yields at all main stem nodes (data not shown). Yield differences for all skip treatments and staggered skips of 30.5 and $61 \mathrm{~cm}$ were compensated by greater yields being produced on position 2 and $\geq 3$ fruiting sites and monopodial branches compared to the uniform planting pattern.

Sixty-seven percent of total yield for the uniform planting pattern was produced on position 1 fruiting sites (Table 5). All other treatments produced from $50 \%$ to $55 \%$ of their total yield on position 1 fruiting sites. Percent of yield produced on position 2 sites across treatments was similar and ranged from $18 \%$ $21 \%$. All treatments with some forms of skip produced a higher percent of their yield on position $\geq 3$ sites and monopodial branches compared to the uniform 
Table 4. Mean lint yield for position (Pos) 1, 2, and $\geq 3$ fruiting sites on sympodial branches, and monopodial (Mon) branches for three experiments (Exp) conducted in 2012-2014 at the Plant Science Research Center Farm, Mississippi State, MS.

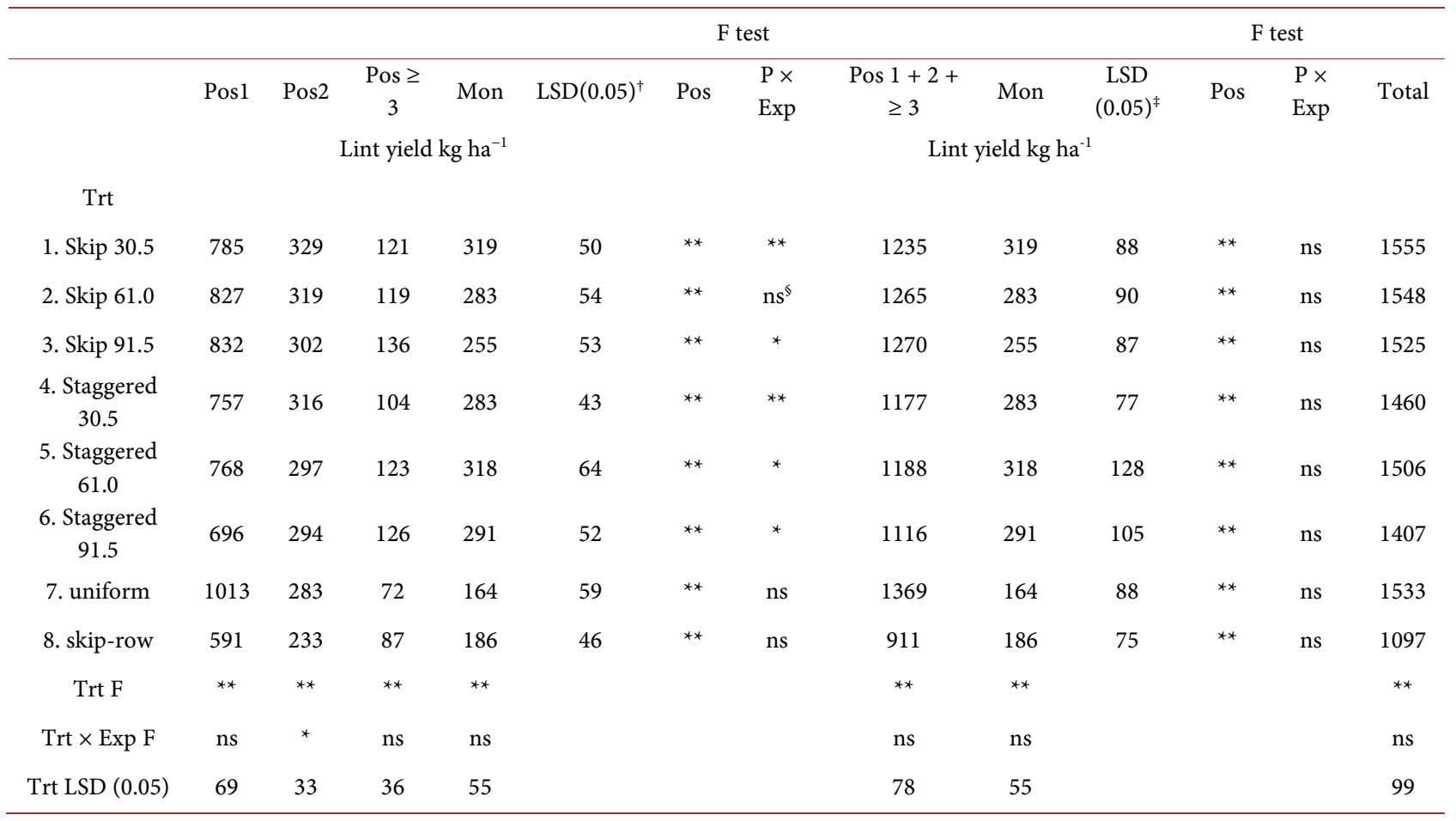

${ }^{*}$, ${ }^{*}$ significant at the 0.05 and 0.01 levels of probability, respectively; ${ }^{\dagger}$ LSD $(0.05)$ for Pos 1 vs Pos 2 vs Pos $\geq 3$ vs monopodial; ${ }^{*} \operatorname{LSD}(0.05)$ for (Pos $1+$ Pos $2+$ Pos $\geq 3$ ) vs monopodial; ${ }^{5} \mathrm{~ns}$, nonsignificant at the 0.05 probability level.

Table 5. Mean percent yield for position (Pos) 1, 2, and $\geq 3$ fruiting sites on sympodial branches, and monopodial (Mon) branches for three experiments (Exp) conducted in 2012-2014 at the Plant Science Research Center Farm, Mississippi State, MS.

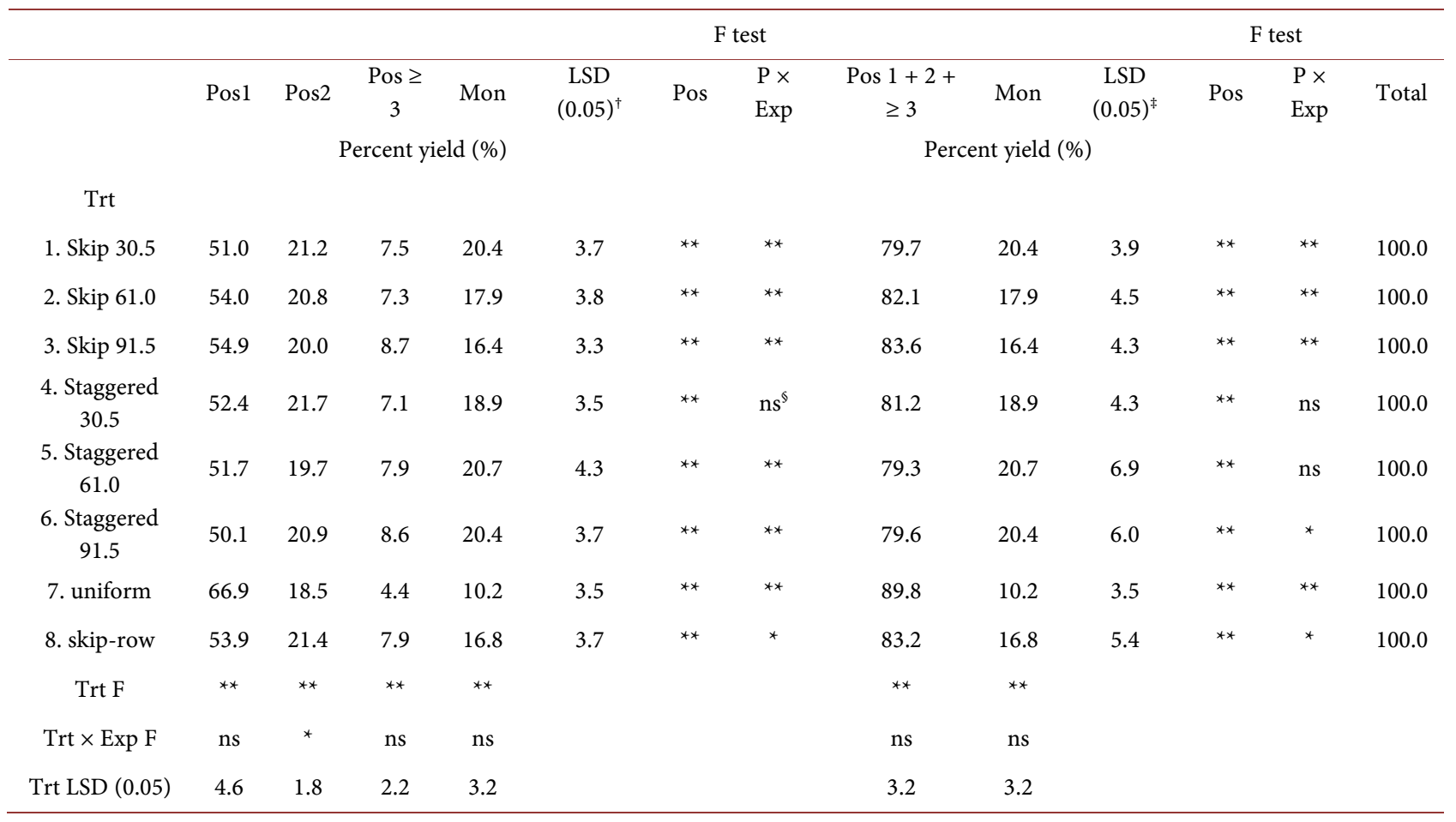

${ }^{*}, * *$ significant at the 0.05 and 0.01 levels of probability, respectively; ${ }^{\dagger}$ LSD $(0.05)$ for Pos1 vs Pos2 vs Pos $\geq 3$ vs monopodial; ${ }^{*}$ LSD $(0.05)$ for (Pos1 + Pos $2+$ Pos $\geq 3$ ) vs monopodial; ${ }^{5} \mathrm{~ns}$, nonsignificant at the 0.05 probability level. 
planting pattern. A higher percent of yield for all skip and staggered skip treatments and skip-row came from monopodial branches and ranged from 16\% $21 \%$ compared to $10 \%$ for the uniform panting pattern treatment (Table 5).

Bolls from position 1 fruiting sites for the uniform planting pattern were more numerous but significantly lighter compared to other treatments (Table 6). All lower plant population treatments had heavier position 1 bolls than the uniform planting pattern. There were no significant differences in boll weight among any treatments for position 2 and $\geq 3$ fruiting sites and monopodial bolls. Monopodial bolls tended to be heavier than those produced on sympodial fruiting sites for most treatments.

The uniform planting pattern produced more position 1 bolls than other treatments (Table 7). Skip and staggered skip treatments produced a similar number of position1 bolls. Lower plant populations, except skip-row, produced more bolls on position 2 and $\geq 3$ fruiting sites and on monopodial braches relative to the uniform planting pattern. Greater compensation occurred as monopodial bolls in lower plant population treatments. This resulted in total number of bolls, except for skip-row, being not significantly different from the uniform planting pattern (Table 7).

Average number of bolls per plant was calculated from machine harvest data and is interesting (Table 8). As the plant stand was reduced about $20 \%$ in skip treatments $1-3$, the number of bolls per plant was $9.1,8.8$, and 8.8 , respectively. For reductions in plants of about $40 \%$, the number of bolls per plant was 11.5 , 10.9, and 11.4 in staggered skip treatments $4-6$, respectively. However, a 50\%

Table 6. Mean boll weight for position (Pos) 1, 2, and $\geq 3$ fruiting sites on sympodial branches, and monopodial (Mon) branches for three experiments (Exp) conducted in 2012-2014 at the Plant Science Research Center Farm, Mississippi State, MS.

\begin{tabular}{|c|c|c|c|c|c|c|c|c|c|c|c|c|}
\hline & & & \multicolumn{8}{|c|}{ F test } & \multicolumn{2}{|c|}{ F test } \\
\hline & Pos1 & Pos2 & $\operatorname{Pos} \geq 3$ & Mon & $\operatorname{LSD}(0.05)^{\dagger}$ & Pos & $\mathrm{P} \times \operatorname{Exp}$ & Pos $1+2+\geq 3$ & Mon & $\operatorname{LSD}(0.05)^{\ddagger}$ & Pos & $\mathrm{P} \times \operatorname{Exp}$ \\
\hline & \multicolumn{7}{|c|}{ Boll weight (g) } & \multicolumn{3}{|c|}{ Boll weight (g) } & & \\
\hline \multicolumn{13}{|l|}{ Trt } \\
\hline 1. Skip 30.5 & 4.31 & 4.16 & 3.80 & 4.68 & 0.29 & $* *$ & $n s^{\S}$ & 4.14 & 4.68 & 0.28 & $* *$ & $\mathrm{~ns}$ \\
\hline 2. Skip 61.0 & 4.24 & 4.19 & 3.84 & 4.37 & 0.29 & $* *$ & ns & 4.13 & 4.37 & 0.20 & * & ns \\
\hline 3. Skip 91.5 & 4.28 & 4.18 & 3.68 & 4.53 & 0.26 & $* *$ & ns & 4.10 & 4.53 & 0.34 & * & ns \\
\hline 4. Staggered 30.5 & 4.22 & 4.06 & 3.60 & 4.57 & 0.27 & $* *$ & ns & 4.02 & 4.57 & 0.23 & $* *$ & ns \\
\hline 5. Staggered 61.0 & 4.29 & 4.13 & 3.83 & 4.71 & 0.23 & $* *$ & * & 4.13 & 4.71 & 0.22 & $* *$ & ns \\
\hline 6. Staggered 91.5 & 4.40 & 4.11 & 3.89 & 4.65 & 0.21 & ** & * & 4.17 & 4.65 & 0.23 & $* *$ & ns \\
\hline 7. uniform & 3.97 & 4.00 & 3.74 & 4.44 & 0.41 & $* *$ & ns & 3.91 & 4.44 & 0.38 & $* *$ & ns \\
\hline 8. skip-row & 4.22 & 3.95 & 3.78 & 4.58 & 0.24 & $* *$ & $\mathrm{~ns}$ & 4.03 & 4.58 & 0.33 & $* *$ & ns \\
\hline Trt F & $* *$ & ns & ns & ns & & & & ns & ns & & & \\
\hline $\operatorname{Trt} \times \operatorname{Exp~F}$ & ns & $\mathrm{ns}$ & ns & ns & & & & ns & ns & & & \\
\hline Trt LSD (0.05) & 0.19 & 0.24 & 0.37 & 0.41 & & & & 0.17 & 0.41 & & & \\
\hline
\end{tabular}

${ }^{*},{ }^{* *}$ significant at the 0.05 and 0.01 levels of probability, respectively; ${ }^{\dagger} \mathrm{LSD}(0.05)$ for Pos 1 vs Pos 2 vs Pos $\geq 3$ vs momopodial; ${ }^{\star} \mathrm{LSD}(0.05)$ for $($ Pos $1+$ Pos $2+$ Pos $\geq 3$ ) vs monopodial; ${ }^{\S}$ ns, nonsignificant at the 0.05 probability level. 
Table 7. Mean number of bolls per hectare for position (Pos) 1, 2 and $\geq 3$ fruiting sites on sympodial branches, and monopodial (Mon) branches for three experiments (Exp) conducted in 2012-2014 at the Plant Science Research Center Farm, Mississippi State, MS.

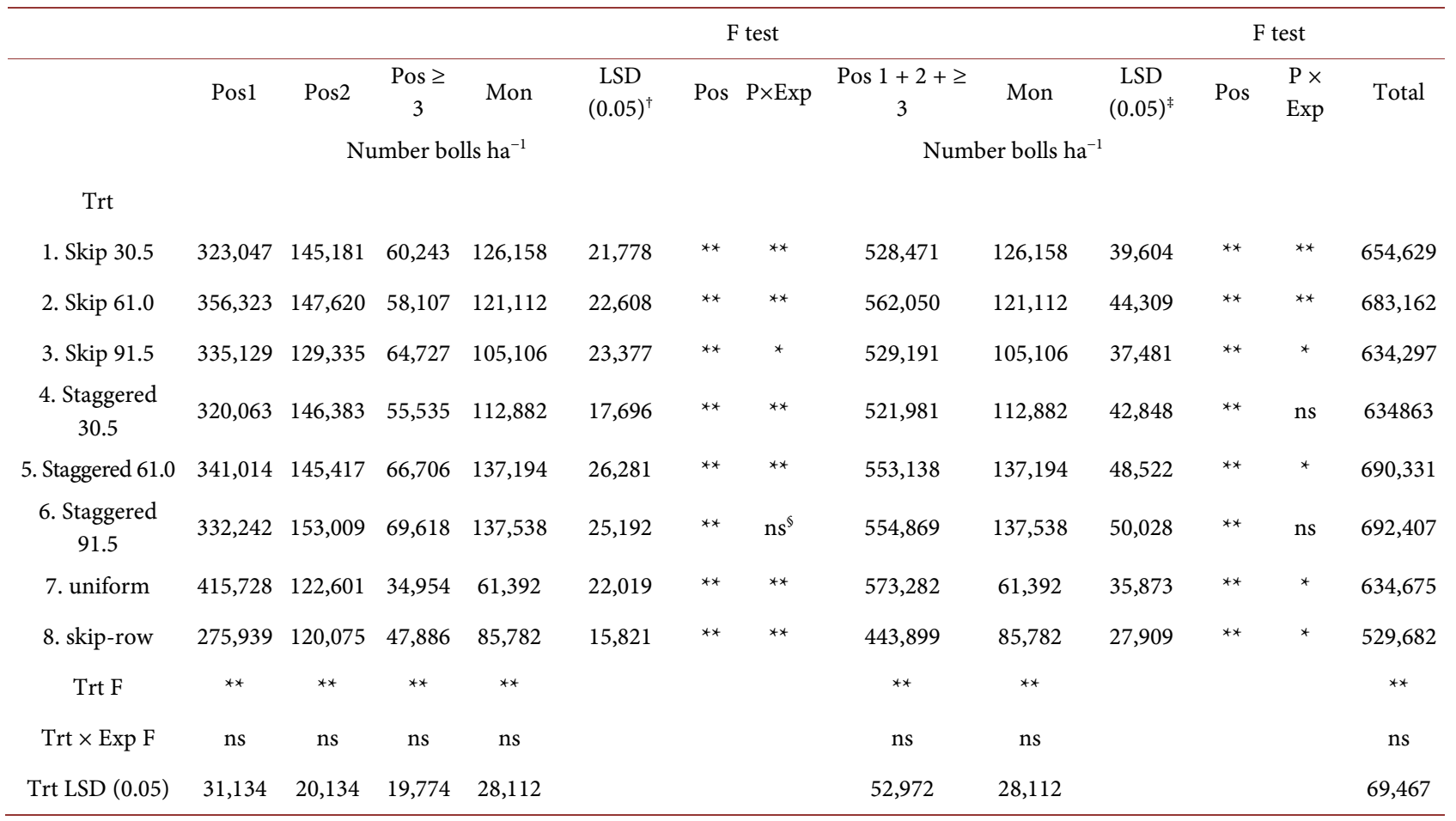

*, ${ }^{* *}$ significant at the 0.05 and 0.01 levels of probability, respectively; ${ }^{\dagger} \mathrm{LSD}(0.05)$ for Pos1 vs Pos2 vs Pos 3 vs momopodial; ${ }^{*} \mathrm{LSD}(0.05)$ for (Pos1+ Pos $2+$ Pos3) vs monopodial; ${ }^{5} \mathrm{~ns}$, nonsignificant at the 0.05 probability level.

Table 8. Machine harvest seed cotton yield, number of bolls, and number of bolls per plant for five experiments conducted in 2012-2014 at the Plant Science Research Center Farm, Mississippi State, MS.

\begin{tabular}{ccccc}
\hline Treatment $^{\dagger}$ & Seed cotton & Bolls $^{\ddagger}$ & Plants & Bolls per plant \\
\hline & $\mathrm{kg} \mathrm{ha}^{-1}$ & Number ha $^{-1}$ & Number ha & Number \\
1. Skip 30.5 & 3480 & 641,214 & 70,453 & 9.1 \\
2. Skip 61.0 & 3466 & 567,323 & 74,750 & 8.8 \\
3. Skip 91.5 & 3434 & 648,680 & 73,523 & 8.8 \\
4. Staggered 30.5 & 3274 & 616,826 & 54,364 & 11.5 \\
5. Staggered 61.0 & 3341 & 616,826 & 56,629 & 10.9 \\
6. Staggered 91.5 & 3155 & 602,623 & 52,854 & 11.4 \\
7. uniform & 3442 & 652,734 & 89,285 & 7.3 \\
8. skip-row & 2448 & 457,050 & 47,096 & 9.8 \\
LSD (0.05) & 221 & 38,387 & & 0.6 \\
\hline
\end{tabular}

†See Table 1 and Table 2 for treatment description; ${ }^{*}$ Number of bolls per hectare was calculated from machine harvest seed cotton yield using average boll weight for the 50 boll sample.

reduction in plants in the skip-row produced 9.8 bolls per plant. These can be compared to the uniform planting pattern where 7.3 bolls were produced per plant. The cotton plant has the ability to compensate, produce and retain more 
open bolls in reduced stands; however, these bolls may be produced later in the growing season. A later maturing crop and the requirement that each plant must produce and mature more bolls in reduced stands could increase production risk. This risk would need to be compared to cost savings of fewer seed in the final decision concerning plant population.

In this three year study our uniform planting pattern stand was about 90,000 plants per hectare from a seeding rate of about 136,000 per hectare (13 seed per $\mathrm{m})$. We used a precision drop planter and commercial seed. The commercial seed had an 80 + percent germination; however, we must remember that standard germination test is conducted under temperature and moisture conditions favorable for germination. Adverse environmental conditions such as cool temperatures and dry and crusty soils can impact stand establishment. Seed quality becomes an important consideration when considering reducing seed rate. Reduced seeding rates coupled with adverse plantings conditions could result in a less than adequate stand resulting in lower yield or in a decision to re-plant. Even though modern precision planting equipments allow accurate seed drop, many interacting factors, some of which cannot be controlled (seed quality, temperature, soil moisture, disease pressure, soil structure, and etc.), determine germination and stand establishment.

The plant one-row skip one-row planting pattern which reduced plant population by $50 \%$ resulted in significant yield losses across five experiments conducted from 2012-2014 compared to the uniform planting pattern of 13 seed per $\mathrm{m}$ of row. Even though down-the-row cost is reduced in skip-row cotton, yields have been reported to be $67 \%$ to $92 \%$ of solid planting depending on soil type and planting pattern [27] [28]. Jost et al. [29] reported in Georgia that skip-row yields averaged $78 \%$ of solid planted across a wide yield range. Skip treatments of $30.5,61$, and $91.5 \mathrm{~cm}$ which reduced stand by about $20 \%$ did not result in lower total yields. Staggered skips of 61 and $91.5 \mathrm{~cm}$ reduced stands about $40 \%$ and resulted in lower yields compared to the uniform planting pattern, when averaged across experiments. However, in some environments (experiments) compensation occurred in the lower plant populations and yields were not reduced. Treatments had minor affects on the yield components boll weight, and lint percentage.

Plant mapping revealed that lower plant stands, compensated with increased boll retention on position 2 and $\geq 3$ fruiting sites and increased retention on monopodial braches. Plants in the uniform planting pattern produced $67 \%$ of its yield from position1 bolls; whereas, skip and staggered skip treatments with $20 \%$ - $40 \%$ reduced stands only produced about $50 \%$ of their total yield on position 1 fruiting sites. On the other hand, skip and staggered skip treatments produced about $20 \%$ of their yield on monopodial branches compared to $10 \%$ for the uniform planting pattern. In some environments this could result in a delay in harvest since position $2, \geq 3$, and monopodial bolls are set later than position 1 bolls. With adverse weather conditions, delayed harvest could result in reduced yield and quality. With modern precision planting equipments opportunities ex- 
ist to reduce seed rate without negatively impacting yield; however, there are risks that must also be considered before a reduced seeding rate is adopted.

\section{Acknowledgements}

This research was conducted in cooperation with the Mississippi Agricultural and Forestry Experiment Station and Mississippi State University. Support for this research was provided by USDA appropriated funds. USDA is an equal opportunity provider and employer. Mention of trade names, brand names, trademark, proprietary product, or vendor does not constitute a guarantee or warranty of the product by the U. S. Department of Agriculture and does not imply its approval to the exclusion of other products or vendors that may also be suitable.

\section{References}

[1] Mayton, E.L., Tisdale, H.B., Bailey, B.Y., Stewart, F., Christor, R.C., Wilson, J.P. and Williamson, J.T. (1937) Cotton Spacing. Circular Number 76, Alabama Polytechnic Institute, Agricultural Experiment Station, 8 p.

[2] Wilkes, L.H. and Corley, T.W. (1968) Planting and Cultivation. In: Elliot, F.C., Hoover, M. and Porter, W.K., Eds., Advances in Production and Utilization of Quality Cotton: Principles and Practices, Iowa State University Press, Ames, 117150.

[3] Bednarz, C.W., Bridges, D.C. and Brown, S.M. (2000) Analysis of Yield Stability across Population Densities. Agronomy Journal, 92, 128-135. https://doi.org/10.2134/agronj2000.921128x

[4] Bednarz, C.W., Shurley, W.D, Anthony, W.S. and Nichols, R.L. (2005) Yield, Quality, and Profitability of Cotton Produced at Varying Plant Densities. Agronomy Journal, 97, 235-240.

[5] Bridge, R.R., Meredith, W.R. and Chism, J.F. (1973) Influence of Planting Method and Plant Population on Cotton (Gossypium hirsutum L.). Agronomy Journal, 65, 104-109. https://doi.org/10.2134/agronj1973.00021962006500010032x

[6] Kerby, T.A., Cassman, K.G. and Keeley, M. (1990) Genotypes and Plant Densities for Narrow-Row Cotton Systems. I. Height, Nodes, Earliness, and Location of Yield. Crop Science, 30, 644-649. https://doi.org/10.2135/cropsci1990.0011183X003000030034x

[7] Mohamad, K.B., Sappenfield, W.P. and Poehlman, J.M. (1982) Cotton Cultivar Response to Plant Populations in a Short-Season, Narrow-Row Cultural System. Agronomy Journal, 74, 619-625. https://doi.org/10.2134/agronj1982.00021962007400040008x

[8] Siebert, J.D., Stewart, A.M. and Leonard, B.R. (2006) Comparative Growth and Yield of Cotton Planted at Various Densities and Configurations. Agronomy Journal, 98, 562-568. https://doi.org/10.2134/agronj2005.0181

[9] Smith, C.W., Waddle, B.A. and Ramey, H.H. (1979) Plant Spacing with Irrigated Cotton. Agronomy Journal, 71, 858-860. https://doi.org/10.2134/agronj1979.00021962007100050035x

[10] O’Berry, N.B., Faircloth, J.J, Edmisten, K.L., Colloins, G.D., Stewart, A.M., Abaye, A.O., Herbert, D.A. and Haygood, R.A. (2008) Plant Population and Planting Date Effects on Cotton (Gossypium hirsutum L.) Growth and Yield. Journal of Cotton 
Science, 12, 178-187.

[11] McCarty, J.C., Cash, L. III and Jenkins J.N. (2011) Effects of Within-Row Plant Spacings on Growth, Boll Retention, and Yield of Four Cotton Cultivars. Bulletin 1191, Mississippi Agricultural \& Forestry Experiment Station, 12 p.

[12] Pettigrew, W.T, Meredith, W.R. and Zeng, L. (2013) Response of Obsolete and Modern Cotton Genotypes to Varying Plant Densities. Journal Cotton Science, 17, 253-262.

[13] Boquet, D.J. and Moser, E.B. (2003) Boll Retention and Boll Size among Intrasympodial Fruiting Sites in Cotton. Crop Science, 43, 195-201.

https://doi.org/10.2135/cropsci2003.1950

[14] Ehlig, C.F and LeMert, R.D. (1973) Effects of Fruit Load, Temperature, and Relative Humidity on Boll Retention of Cotton. Crop Science, 13, 168-171. https://doi.org/10.2135/cropsci1973.0011183X001300020006x

[15] Guinn, G. (1985) Fruiting of Cotton. III. Nutritional Stress and Cutout. Crop Science, 25, 981-985. https://doi.org/10.2135/cropsci1985.0011183X002500060020x

[16] Reddy, K.R., Hodges, H.F. and Reddy, V.R. (1992) Temperature Effects on Cotton Fruit Retention. Agronomy Journal, 84, 26-30. https://doi.org/10.2134/agronj1992.00021962008400010006x

[17] Peoples, T.R. and Matthews, M.A. (1981) Influence of Boll Removal on Assimilate Partitioning in Cotton. Crop Science, 21, 283-286. https://doi.org/10.2135/cropsci1981.0011183X002100020019x

[18] Pettigrew, W.T. (1994) Source-to-Sink Manipulation Effects on Cotton Lint Yield and Yield Components. Agronomy Journal, 86, 731-735. https://doi.org/10.2134/agronj1994.00021962008600040027x

[19] Boquet, D.J., Moser, E.B. and Breitenbeck, G.A. (1994) Boll Weight and WithinPlant Yield Distribution in Field-Grown Cotton Given Different Levels of Nitrogen. Agronomy Journal, 86, 20-26. https://doi.org/10.2134/agronj1994.00021962008600010005x

[20] Jenkins, J.N. and McCarty, J.C. (1995) Useful Tools in Managing Cotton Production: End of Season Plant Maps. Bulletin 1024, Mississippi Agricultural \& Forestry Experiment Station, $21 \mathrm{p}$.

[21] Jenkins, J.N., McCarty, J.C. and Parrott, W.L. (1990a) Fruiting Efficiency in Cotton: Boll Size and Boll Set Percentage. Crop Science, 30, 857-860. https://doi.org/10.2135/cropsci1990.0011183X003000040018x

[22] Jenkins, J.N., McCarty, J.C. and Parrott, W.L. (1990b) Effectiveness of Fruiting Sites in Cotton: Yield. Crop Science, 30, 365-369. https://doi.org/10.2135/cropsci1990.0011183X003000020024x

[23] USDA-AMS (2011) Cotton Varieties Planted, 2011 Crop. USDA-AMS mp_cn833. Memphis, TN.

[24] McIntosh, M.S. (1983) Analysis of Combined Experiments. Agronomy Journal, 75, 153-155. https://doi.org/10.2134/agronj1983.00021962007500010041x

[25] Heilman, M.D., Namken, L.N. and Cantu, R.V. (1976) Effects of Stand Loss on Lint Cotton Yields in Single and Double Drilled Rows. Proceedings of the Beltwide Cotton Conferences, Las Vegas, 5-7 January 1976, 101-102.

[26] Supak, J.R. and Wanjura, D.T. (1988) Influence of Skippy Stands on Lint Yields and Fiber Quality. Proceedings of the Beltwide Cotton Conferences, New Orleans, 3-8 January 1988, 108-109.

[27] Stephens, D., Parvin, D.W. and Cooke, F.T. (2000) The Impact of Narrow Skip-Row 
Cotton on Cost Per Pound. Proceedings of the Beltwide Cotton Conferences, San Antonio, 4-8 January 2000, 295-298.

[28] Parvin, D.W., Martin, S.W. and Cooke, F.T. (2003) The Effect of Tillage Systems, Row Spacing, Equipment Size, Soil Group and Variety Type on Yields, Costs and Returns, Mississippi Delta. Proceedings of the Beltwide Cotton Conferences, Nashville, 6-10 January 2003, 450-460.

[29] Jost, P., Brown, S.M. Shurley, D., McDaniel, R. and McNeill, B. (2003) Evaluation of Skip Row Cotton in Georgia. Proceedings of the Beltwide Cotton Conferences, Nashville, 6-10 January 2003, 1700-1703.

Submit or recommend next manuscript to SCIRP and we will provide best service for you:

Accepting pre-submission inquiries through Email, Facebook, LinkedIn, Twitter, etc. A wide selection of journals (inclusive of 9 subjects, more than 200 journals) Providing 24-hour high-quality service User-friendly online submission system Fair and swift peer-review system Efficient typesetting and proofreading procedure Display of the result of downloads and visits, as well as the number of cited articles Maximum dissemination of your research work

Submit your manuscript at: http://papersubmission.scirp.org/

Or contact ajps@scirp.org 